\title{
Ozonation of wastewater: Removal and transformation products of drugs of abuse
}

\author{
Angela Rodayan, Pedro Alejandro Segura, Viviane Yargeau * \\ Department of Chemical Engineering, McGill University, 3610 University Street, Montreal, Quebec, Canada, H3A 2 B2
}

\section{H I G H L I G H T S}

- The ozonation of six drugs of abuse and one human drug metabolite was carried out.

- Drug removals vary between 3 and 50\% for the ozone doses tested.

- The main transformation products of the drugs of abuse were identified.

- The most plausible structure of a transformation product of MDMA was elucidated.

\section{A R T I C L E I N F O}

\section{Article history:}

Received 30 July 2013

Received in revised form 18 October 2013

Accepted 4 November 2013

Available online 7 December 2013

\section{Keywords:}

Drugs of abuse

Wastewater

Ozone

Cocaine

Amphetamines

High resolution mass spectrometry

\begin{abstract}
A B S T R A C T
In this study amphetamine, methamphetamine, methylenedioxymethamphetamine (MDMA), cocaine (COC), benzoylecgonine (BE), ketamine (KET) and oxycodone (OXY) in wastewater at concentrations of $100 \mu \mathrm{gL}^{-1}$ were subjected to ozone to determine their removals as a function of ozone dose and to identify significant oxidation transformation products (OTPs) produced as a result of ozonation. A method based on high resolution mass spectrometry and differential analysis was used to facilitate and accelerate the identification and structural elucidation of the transformation products. The drug removal ranged from 3 to $50 \%$ depending on the complexity of the matrix and whether a mixture or individual drugs were ozonated. Both transient and persistent oxidation transformation products were identified for MDMA, COC and OXY and their chemical formulae were determined. Three possible structures of the persistent transformation product of MDMA (OTP-213) with chemical formula $\mathrm{C}_{10} \mathrm{H}_{16} \mathrm{O}_{4} \mathrm{~N}$, were determined based on $\mathrm{MS}^{\mathrm{n}}$ mass spectra and the most plausible structure (OTP-213a) was determined based on the chemistry of ozone. These results indicate that ozone is capable of removing drugs of abuse from wastewater to varying extents and that persistent transformation products are produced as a result of treatment.
\end{abstract}

C 2013 Elsevier B.V. All rights reserved.

\section{Introduction}

Wastewater treatment plants (WWTPs) have been designed to reduce carbon and nitrogen loads in sewage water. Recently however, several classes of micropollutants have been detected in wastewaters but the treatment systems are not equipped to remove them and they are therefore discharged to receiving waters either unaltered or as metabolites, making wastewater effluents important point sources of contamination (Pedrouzo et al., 2011b; Valcárcel et al., 2012).

Although much work has been done to determine the occurrence of pharmaceuticals and other contaminants of emerging concern (CECs) in wastewater and their fate during wastewater treatment (Boxall et al., 2012; Camacho-Muñoz et al., 2010; de Jongh et al., 2012; Kolpin et al., 2002; Metcalfe and Koenig, 2003; Ternes, 1998), the data available for drugs of abuse (DOAs) and their metabolites are far more scarce. It is

\footnotetext{
* Corresponding author. Tel: +1 5143982273.

E-mail address: viviane.yargeau@mcgill.ca (V. Yargeau).
}

well known however, that the use of psychoactive substances is essentially universal and that they are one of the most recent additions to the list of contaminants of emerging concern in the environment (Boleda et al., 2009; Kasprzyk-Hordern et al., 2010). It is clear from the studies that have identified these compounds in wastewater effluents and surface waters at the nanogram and in some cases, microgram per liter level, that they and many of their main human metabolites, are ubiquitous in the environment (Baker and Kasprzyk-Hordern, 2011; Bartelt-Hunt et al., 2009; Bijlsma et al., 2012, 2013; Castiglioni et al., 2006a; Gheorghe et al., 2008; González-Mariño et al., 2011; Hummel et al., 2006; Jones-Lepp et al., 2004; Kasprzyk-Hordern et al., 2009; Metcalfe et al., 2010; Pedrouzo et al., 2011a; Postigo et al., 2011; Zuccato et al., 2005). In fact, these compounds, like many other contaminants of emerging concern have been shown to be resistant to physicochemical and biological treatment at WWTPs and are therefore continuously introduced into the aquatic environment (Boleda et al., 2009; Bolong et al., 2009; Chiaia et al., 2008; Huerta-Fontela et al., 2008; Pal et al., 2013; Postigo et al., 2010; Valcárcel et al., 2012; Yargeau et al., 2013; 
Zuccato et al., 2008). These compounds have also been detected in surface waters in many countries (Boleda et al., 2011; Gonzalez-Marino et al., 2010; Martínez Bueno et al., 2011; Terzic et al., 2010; Valcárcel et al., 2012) and since illicit drugs have psychoactive properties, their presence in the aquatic environment raises concern (Huerta-Fontela et al., 2012). In addition, the potential for adverse effects exists due to the presence of these and other compounds as complex mixtures in the environment and multi-generational exposure of aquatic organisms (Kantiani et al., 2010). There also exists a potential for negative effects on humans since surface waters are often used as raw sources of drinking water as well as concerns in water reuse since these compounds can accumulate if they are not properly removed (Bolong et al., 2009; Halling-Sørensen et al., 1998). The above knowledge on the presence and potential impact of contaminants of emerging concern demonstrates the need to upgrade wastewater treatment plants and improve wastewater treatment technologies.

One approach to reduce the load of these compounds released in the environment is to treat contaminants of emerging concern at their major entry point which is the effluent from WWTPs (Joss et al., 2008). In order to reduce the loads of these compounds in wastewater effluent, the conventional wastewater treatment process must be improved by implementing new treatment technologies that are capable of efficiently removing these, and other, compounds of interest. Such technologies include, among others: UV disinfection, activated carbon adsorption, ion exchange, electrodialysis, membrane filtration and separation and advanced oxidation processes (AOPs). These treatment systems have been shown to efficiently remove compounds that remain in wastewater after secondary treatment, such as: pharmaceuticals, endocrine-disrupting chemicals, iodinated X-ray contrast media and musk fragrances (Huber et al., 2003; Larcher and Yargeau, 2013; McDowell et al., 2005; Nakada et al., 2007; Rodayan et al., 2010; Ternes et al., 2003; Zwiener and Frimmel, 2000). Due to the strong oxidizing power of hydroxyl radicals, AOPs such as photocatalysis, ozonation and photo-Fenton systems are of particular interest for the removal or transformation of contaminants of emerging concern (Akmehmet Balcıoğlu et al., 2003; Boleda et al., 2011; Comninellis et al., 2008; Gogate and Pandit, 2004; Nasuhoglu et al., 2012; Valcárcel et al., 2012).

Ozone $\left(\mathrm{O}_{3}\right)$ is a selective oxidant that is reactive towards double bonds, aromatic systems, non-protonated secondary and tertiary amines, and reduced sulfur species (Hollender et al., 2009). In addition, hydroxyl radicals that are formed by the decomposition of ozone also add to the oxidizing potential of the ozonation process (von Gunten, 2003). From an economic standpoint, Joss et al. (2008) considered the implementation of an ozonation treatment setup to be quite feasible in terms of energy and cost given that the total estimated cost of ozonation is between 0.05 and $0.20 €$ per $\mathrm{m}^{3}$ of wastewater which does not consist a large part of the total cost of maintaining a WWTP (of course depending on the size of the plant and the level of dissolved organic carbon remaining in the treated water). Hollender et al. (2009) showed that operational costs for ozone treatment systems can be estimated based on the ozone doses determined at the laboratory scale, therefore making such experiments essential to the understanding of ozone application at WWTPs.

Ozonation of drinking water and wastewater for disinfection is well established in some parts of the world, especially Europe, but its potential to remove contaminants of emerging concern has only been investigated more recently (Rosal et al., 2010). It has already been shown that ozonation is effective at removing several micropollutants to more than $95 \%$ that are not typically removed during conventional activated sludge treatment, therefore making it a promising option to remove these compounds (Huber et al., 2005; Nakada et al., 2007; Rodayan et al., 2010; Ternes et al., 2003; Wert et al., 2009). Rosal et al. (2010) investigated the removal of the DOA codeine in wastewater during ozonation and found that a dose of $\angle 50 \mu \mathrm{M}$ was required to decrease the concentration of the drug to below $5 \mu \mathrm{gL}^{-1}$ which was the limit of quantification (LOQ) of the method used. To our knowledge, no other study has investigated the potential to remove DOAs in wastewater using ozone.

An issue that arises from the application of ozonation and other oxidation techniques to treat wastewater is the potential transformation products that are produced as a result of incomplete mineralization of the organic compounds in aqueous solution and their potential toxicity (Klavarioti et al., 2009). Huerta-Fontela et al. (2012) showed that disinfection by-products are produced after chlorine oxidation of amphetaminetype compounds at a drinking water treatment plant but in most studies the fate of the parent compound is monitored and the transformation products are generally not identified nor quantified (Celiz et al., 2009). It has been shown however that degradation by-products often persist after the parent compound has been completely removed and in some cases they are more toxic to aquatic organisms than the parent compound (Dantas et al., 2007; Gomez-Ramos et al., 2011; Rosal et al., 2010). Since it is not economically feasible to implement an ozonation system to supply enough ozone for complete mineralization, before ozone is implemented at WWTPs for either disinfection purposes or for the removal (or transformation) of CECs, the potential oxidation transformation products (OTPs) must first be investigated. It must be proven that these OTPs are either nontoxic (or at least less toxic than the parent compound) or are easily degraded (Joss et al., 2008).

The objective of this work was to obtain the first removal profiles of selected drugs of abuse in pure water (reverse osmosis water) and wastewater effluent as a function of ozone dose and to investigate the presence of OTPs in the treated water using high-resolution multistage tandem mass spectrometry $\left(\mathrm{HRMS}^{\mathrm{n}}\right)$ and differential analysis. The chemical structures of the six drugs of abuse and one human metabolite considered in this study are shown in Fig. 1 along with some physicochemical properties of the selected compounds. These DOAs were selected based on their worldwide consumption (UNODC, 2008) and detection in wastewater effluents in a previous Canadian study as well as in studies conducted in other countries (Boleda et al., 2007; Bones et al., 2007; Castiglioni et al., 2006b; Gheorghe et al., 2008; HuertaFontela et al., 2007; Hummel et al., 2006; Irvine et al., 2011; KasprzykHordern et al., 2009; Metcalfe et al., 2010; Pedrouzo et al., 2011a; Postigo et al., 2011; Zuccato and Castiglioni, 2009). In addition, it has been shown that COC has cyto-genotoxic effects on Dreissena polymorpha (zebra mussel) at environmentally relevant concentrations. To our knowledge, ecotoxicity results have not been reported for the other DOAs considered in this study.

\section{Methodology}

\subsection{Chemicals and reagents}

Analytical standards of all compounds studied and their stable isotopes are listed in Table 1. The deuterated stable isotope standards of each compound were used as surrogates to correct for extraction recoveries and, in the case of wastewater, matrix effects as well. All standards were supplied by Cerilliant (Austin, TX, USA) with purity higher than 99\%. Standards of compounds and surrogates were obtained at $1 \mathrm{~g} \mathrm{~L}^{-1}$ and $100 \mu \mathrm{g} \mathrm{mL}^{-1}$ respectively, in methanol with the exception of cocaine which was supplied in acetonitrile at the same concentrations. All standards and working solutions were stored in amber glass bottles at $-20^{\circ} \mathrm{C}$. Working solutions were allowed to thaw in the fridge prior to use but standards were used directly from the freezer since they were in pure solvent.

Ultrapure water obtained using a Milli-Q water purification system from Millipore (Bedford, MA, USA) was used to prepare working solutions and drug stock solutions. Optima liquid chromatography-mass spectrometry (LC-MS) grade methanol, acetonitrile, and water, high performance liquid chromatography (HPLC grade or equivalent) acetone as well as ACS reagent grade sulfuric acid (96\%) and formic acid (88\%) and trace metal grade ammonium hydroxide (88\%) were purchased from Fisher Scientific (Ottawa, ON, Canada). 
<smiles>CC(N)Cc1ccccc1</smiles>

Amphetamine (AMP, speed) $\mathrm{MW}=135, \mathrm{pK}_{\mathrm{a}}=10.1$ $\log \mathrm{K}_{\mathrm{ow}}=1.76$

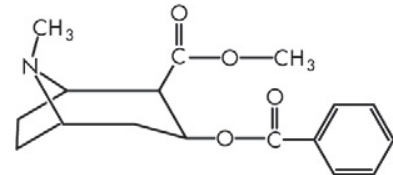

Cocaine (COC) $\mathrm{MW}=303, \mathrm{pK}_{\mathrm{a}}=8.6$ $\log \mathrm{K}_{\mathrm{ow}}=2.30$<smiles>CNC1(c2ccccc2Cl)CCCCC1=O</smiles>

Ketamine (KET) $\mathrm{MW}=237, \mathrm{pK}_{\mathrm{a}}=7.5$ $\log \mathrm{K}_{\mathrm{ow}}=3.12$<smiles>CNC(C)Cc1ccccc1</smiles>

Methamphetamine (METH) $\mathrm{MW}=149, \mathrm{pK}_{\mathrm{a}}=9.7$

$\log \mathrm{K}_{\mathrm{ow}}=1.64$<smiles>CN1C2CCC1C(C(=O)O)C(OC(=O)c1ccccc1)C2</smiles>

Benzoylecgonine (BE)

$\mathrm{MW}=289, \mathrm{pK}_{\mathrm{a}}=10.1 / 3.6$

$\log \mathrm{K}_{\mathrm{ow}}=<0$<smiles>CNC(C)Cc1ccc2c(c1)OCO2</smiles>

MDMA (ecstasy)

$\mathrm{MW}=193, \mathrm{pK}_{\mathrm{a}}=9.9$

$\log \mathrm{K}_{\mathrm{ow}}=2.28$

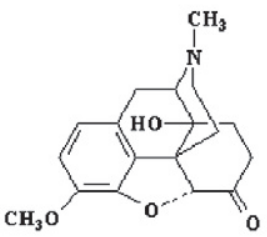

Oxycodone (OXY)

$\mathrm{MW}=315, \mathrm{pK}_{\mathrm{a}}=8.53$

$\log \mathrm{K}_{\mathrm{ow}}=0.66$

Fig. 1. Structures and physicochemical properties of the selected compounds.

\subsection{Wastewater sample collection}

Grab samples of the effluent of a secondary wastewater treatment plant in Gatineau, Québec, Canada were collected in November 2011 and were used for all experiments performed on wastewater in this study. The treatment at the plant includes screening, grit removal, primary clarification, biological treatment and finally secondary clarification. The average flow received by the plant is $127,400 \mathrm{~m}^{3} \mathrm{~d}^{-1}$ (2011) and it serves a population of approximately 235,000 inhabitants. The concentration of suspended solids in the treated water was measured to be $5.9 \mathrm{mg} \mathrm{L}^{-1}$ using Standard Method \#2540D. The chemical oxygen demand was measured to be $39 \mathrm{mg} / \mathrm{L}$ using a HACH Digital Reactor Block 200 (DRB 200) and a HACH spectrophotometer DR/2500. Average data for biochemical oxygen demand $\left(\mathrm{BOD}_{5}\right)$ and total phosphorus were obtained by plant personnel and were 3.9 and $0.41 \mathrm{mg} \mathrm{L}^{-1}$, respectively. Samples were collected in $1 \mathrm{~L}$ pre-cleaned amber glass bottles. Following collection, samples were stored in a cooler at $4{ }^{\circ} \mathrm{C}$ during transportation to academic laboratory facilities where they were then stored at $-20{ }^{\circ} \mathrm{C}$ until used for experiments.

Table 1

Selected DOAs and corresponding surrogates used for quantification.

\begin{tabular}{ll}
\hline Compound & Surrogates \\
\hline Cocaine & Cocaine- $\mathrm{d}_{3}$ \\
Benzoylecgonine & Benzoylecgonine- $\mathrm{d}_{8}$ \\
Amphetamine & Ampehtamine- $\mathrm{d}_{8}$ \\
Methamphetamine & Methamphetamine- $\mathrm{d}_{9}$ \\
MDMA & MDMA- $\mathrm{d}_{5}$ \\
Ketamine & Ketamine- $\mathrm{d}_{4}$ \\
Oxycodone & Oxycodone- $\mathrm{d}_{6}$ \\
\hline
\end{tabular}

\subsection{Ozonation}

Batch ozonation experiments were carried out using a concentrated ozone stock solution. A $500 \mathrm{~mL}$ gas washing bottle filled with pure water and placed in a bucket filled with ice was sparged with a gas mixture of ozone and oxygen gas. Ozone was produced by feeding pure oxygen to an OZO4VTT Ozomax generator (Granby, Qc). The dissolved ozone concentration was determined spectrophotometrically at an absorbance of $258 \mathrm{~nm}$ and using a molar absorptivity value of $2950 \mathrm{M}^{-1} \mathrm{~cm}^{-1}$ (Bader and Hoigne, 1981). Once the concentration of ozone in water was measured, the required volume of ozone stock solution was added to the experimental stock solution of each compound of interest. Ozone experiments for all compounds were carried out in triplicate with ozone to drug molar ratios of $0: 1,1: 2,1: 1,2: 1,4: 1$ and $8: 1$ which correspond to different $\mathrm{mg} \mathrm{L}^{-1}$ doses depending on the molecular weight of the compound but in the range 0.01 to $0.30 \mathrm{mg} \mathrm{O}_{3} \mathrm{~L}^{-1}$. Individual solutions in pure water and a mixture of all compounds in pure water and wastewater at $100 \mu \mathrm{g} \mathrm{L}{ }^{-1}$ were subjected to ozonation. It is important to note that in the case of samples in wastewater, the initial concentration of $100 \mu \mathrm{g} \mathrm{L}^{-1}$ is the total concentration of the DOA, therefore taking into account the level of each DOA in the wastewater sample obtained from the treatment plant. This concentration was chosen so that the levels of the DOAs were as close as possible to the ones reported in wastewater effluent (Bijlsma et al., 2009; Huerta-Fontela et al., 2007; Martínez Bueno et al., 2011; Nuijs et al., 2009; Pal et al., 2013) but also considering the limitation associated with the LOQs for each compound and the volume of wastewater required for ozonation experiments and sample pre-concentration. For ease of OTP identification and structural elucidation, additional ozonation experiments were performed using individual solutions in pure water at $5 \mathrm{mg} \mathrm{L}^{-1}$ were also conducted. However, to ensure that the reaction pathways between ozone and the compounds of interest at the high concentration of $5 \mathrm{mg} \mathrm{L}^{-1}$ were identical to those at concentrations similar 
to those found in wastewater effluents and, to evaluate matrix effects on OTP production, ozonation of unspiked wastewater effluent containing the compounds of interest was carried out. Once the appropriate volume of ozone stock solution was added to each flask, they were wrapped in aluminum foil to avoid exposure to light, covered to avoid contamination (not sealed) and mixed for $30 \mathrm{~min}$ to ensure that all of the ozone had reacted and had dissipated from solution. The reaction time was set to $30 \mathrm{~min}$ based on previous experiments that showed that after $12 \mathrm{~min}$ ozone (at the highest dose used) was no longer measurable in solution and therefore no further reaction is expected.

\subsection{Sample pre-concentration}

Ozonated solutions with an initial drug concentration of $100 \mu \mathrm{g} \mathrm{\textrm {L } ^ { - 1 }}$ and ozonated wastewater samples required pre-concentration using solid phase extraction (SPE) prior to LC-MS analysis. Ozonated samples were acidified to a pH of 2.5 using $3.5 \mathrm{M}$ sulfuric acid and in the case of wastewater samples; these were first vacuum filtered through $1.5 \mu \mathrm{m}$ glass-fiber filters. Each sample was then spiked with $100 \mu \mathrm{L}$ of a $500 \mathrm{ng} \mathrm{mL} \mathrm{m}^{-1}$ surrogate mixture and well mixed. Procedural blanks in each matrix were also pre-concentrated to measure SPE recovery of both the DOAs and their surrogates. Automated SPE was carried out using a Gilson GX-271 ASPEC ${ }^{\mathrm{TM}}$ instrument using the method described in Metcalfe et al. (2010). The eluent was then evaporated to almost dryness using a Savant SPD 131DDA Speed Vac Concentrator connected to a RVT4104 refrigerated vapor trap (Thermo Fisher Scientific, Waltham, MA). As a final step, the sample was reconstituted to a volume of $0.4 \mathrm{~mL}$ in $25 \%$ water $/ 75 \%$ methanol. SPE recoveries for all compounds and their surrogates were $>80 \%$ and are listed in the Supplemental Material. A $25 \mu \mathrm{L}$ aliquot of the sample extract was injected directly into the LC-MS system for analysis.

\subsection{Quantitative analysis}

Analyte concentrations were measured by liquid chromatographyhigh resolution mass spectrometry (LC-HRMS) using an Accela LC system coupled to a LTQ Orbitrap XL (Thermo Fisher Scientific, Waltham, MA). Prior to injection into the LC-HRMS system, samples with initial drug concentration of $5 \mathrm{mg} \mathrm{L}^{-1}$ were diluted ten times in $25 \%$ water/75\% methanol while other samples were injected without additional preparation Chromatographic separation of the compounds was achieved using a Hypersil Gold column $(50 \times 2.1 \mathrm{~mm}, 1.9 \mu \mathrm{m})$ with an in-line DirectConnection UHPLC $0.2 \mu \mathrm{m}$ filter. An optimized gradient of 5\% methanol in water (solvent A) and acetonitrile (solvent B) both with $0.1 \%$ acetic acid at a flow of $0.3 \mathrm{~mL} \mathrm{~min}{ }^{-1}$ was used. The percentage of organic (B) was changed as follows: $0 \mathrm{~min}$ (10\%), $1.75 \mathrm{~min}(10 \%) 3.05$ (25\%), $5.55 \mathrm{~min}$ (97\%), $7.55 \mathrm{~min}$ (97\%), $7.75 \mathrm{~min}$ (10\%), and $16.00 \mathrm{~min}(10 \%)$. Ionization was done in positive mode using a heated electrospray ionization (HESI) source and all data were acquired and processed using XCalibur 2.1 software.

\subsection{Identification of oxidation transformation products}

The method used to identify potential oxidation transformation products significantly reduces the time required to sift through all of the data obtained by HRMS and is described in detail in Segura et al. (2013). Briefly, the main potential OTPs of each compound of interest are identified using the differential expression analysis software Sieve 2.0 (Thermo Scientific). The "control compare trend" feature was used whereby the following settings were adjusted for each compound of interest: $m / z$ range, $m / z$ width, retention time range, retention time width, maximum number of frames and signal threshold. Additionally such an experiment allows the user to observe changes in the intensity of each frame in the samples. These intensity trends can be used to identify potential OTPs (for example OTPs are expected to increase in intensity as a function of ozone dose). Elemental formulas of the exact masses of the signals of the potential OTPs were obtained in the QualBrowser program of XCalibur 2.1 using the "Elemental composition" tab. This task was facilitated by specifying the possible range of hydrogen, carbon, nitrogen and oxygen atoms that the chemical formula could contain based on the chemical formula of the parent compound and its reaction with ozone.

\subsection{Structural elucidation of oxidation transformation products}

Once the potential OTPs are identified, their structures are elucidated by the infusion of high concentration $\left(5 \mathrm{mg} \mathrm{L}^{-1}\right)$ ozonated samples directly into the mass spectrometer and by carrying out high resolution multi-stage tandem mass spectrometry $\left(H R M S^{n}\right)$ experiments. The ion tree generation experiment was used to elucidate the structure of the persistent OTP of MDMA, OTP-213. This experiment consists of a series of data-dependent experiments that are automatically triggered when the predefined conditions are met. The first step that is performed is a narrow full scan experiment $(\mathrm{m} / \mathrm{z} 210-235)$. When the ion of interest is found (in this case $m / z 214$ ), a data-dependent experiment is triggered which results in the collision-induced dissociation (CID) of $m / z$ 214 and the $\mathrm{MS}^{2}$ spectrum is acquired. From the five most intense first generation product ions of the $\mathrm{MS}^{2}$ spectrum (the precursor ion is excluded), $\mathrm{MS}^{3}$ experiments are then initiated and their respective spectra are acquired. From the $\mathrm{MS}^{3}$ spectra only the most intense second generation product ion is selected for a final $\mathrm{MS}^{4}$ experiment. The ion tree generation experiment thus results in an ion tree with one branch for the $\mathrm{MS}^{2}$ experiment, five branches for the $\mathrm{MS}^{3}$ stage and one branch for the $\mathrm{MS}^{4}$ stage. Normalized activation energy was set to 35 , isolation width to $2 \mathrm{~m} / z$ and activation time to $30 \mathrm{~ms}$. The file was subsequently deconvoluted with Mass Frontier 7.0 (HighChem Ltd., Bratislava, Slovakia). Once the ion tree of OTP-213 was deconvoluted, structures were assigned to the MS ${ }^{\mathrm{n}}$ product ions using the Fragments and Mechanisms feature in Mass Frontier. This feature uses known and theoretical fragmentation mechanisms to predict product ions from a proposed structure.

\section{Results and discussion}

\subsection{DOA removal during ozonation}

Removal profiles as a function ozone dose were generated from the data obtained by ozonation experiments conducted using a mixture of the seven DOAs in wastewater at an initial concentration of $100 \mu \mathrm{g} \mathrm{L} \mathrm{L}^{-1}$. Treated wastewater was used to account for matrix effects during the ozonation of the DOAs since it is well known that wastewater composition can influence the removals of target compounds during treatment. The removal profiles are shown in Fig. 2 where the data are presented as a ratio of the residual drug concentration as a function of ozone dose applied to the solution. Each point on the graph represents the average of triplicate experiments performed by subjecting the drug mixture to the specific ozone dose required to achieve the molar ratio for the compound being considered in that profile.

It is clear from Fig. 2 that the compounds are removed to varying extents. In the case of benzoylecgonine, at an ozone to drug ratio of $4: 1$, $96 \%$ of the drug remains and this value does not change significantly at a ratio of $8: 1$ therefore, $\mathrm{BE}$ may be considered to be persistent to ozone. The profiles of AMP and KET show that both drugs are removed less than $25 \%$ at the highest ozone dose tested and in the case of AMP a concentration plateau is observed starting at the $4: 1$ data point whereas the KET concentration continues to follow a decreasing trend at the 8:1 ratio. In cases where a concentration plateau is observed regardless of the ozone dose applied, it is thought that there is competition for the reaction with ozone from other compounds in solution, such as the OTPS that are formed which may be more reactive to ozone than the parent compounds. COC and METH are removed to $70 \%$ of their initial concentration. COC exhibits a large decrease at lower ozone doses and its concentration does not decrease significantly after a ratio of 1:1. MDMA and 


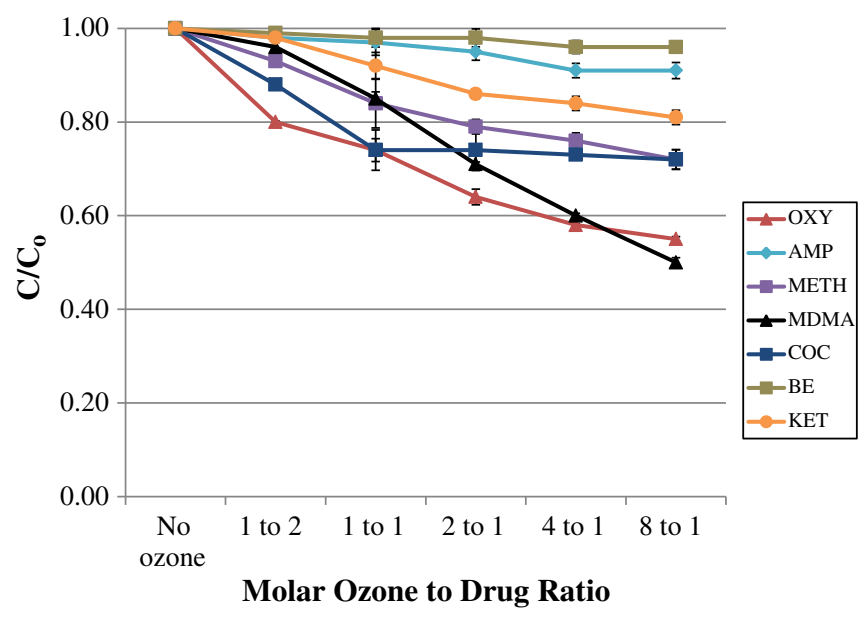

Fig. 2. Removal profiles of selected DOAs with $C_{o}=100 \mu \mathrm{g} \mathrm{L}^{-1}$ in wastewater as a function of molar ozone to drug ratio (each data point represents an average of triplicate experiments and error bars correspond to one standard deviation).

OXY were removed to 50 and $45 \%$ respectively and their profiles show that the decreasing concentration trends observed in both cases continue at a ratio of 8:1, leading one to expect that if high enough ozone doses were applied, these compounds would be completely removed or transformed.

There is a notable difference between the removals of AMP (9\%) and METH (30\%) at the highest ozone dose tested but the only difference in their structures is that AMP has a primary amine while METH has a secondary amine. The nitrogen atom is electron withdrawing and is therefore able to pull electrons from the ring which is the main reaction site for ozone in both compounds. However, in the case of METH, this effect is weakened by the presence of the secondary amine. The presence of the methyl group gives the nitrogen atom a slightly more negative charge since alkyl groups have the tendency to push electrons away from themselves and in this case, towards the nitrogen atom. Since the nitrogen in METH has a more negative charge, it has less desire to pull electrons from the ring, allowing the molecule to remain more reactive to ozone than AMP (Decoret et al., 1984).

There was also a significant difference between the removals of $\mathrm{BE}$ and COC which were 4 and 30\% respectively. Again, there is only a small structural difference between the two compounds but it seems to have a significant effect on their reactivity with ozone. The carboxylic acid in BE is replaced with an ester bond in COC. Ozone attack is usually on the benzene ring if it is present in a molecule, however, it is well known that the nature of the substituent on the ring is a strong contributor to the ring's reactivity to ozone (Decoret et al., 1984). In the case of $\mathrm{COC}$ and $\mathrm{BE}$ there is no structural difference in that area of the molecule but both have an ester group as a ring substituent. Therefore, for a reason that we are not able to explain, the presence of the carboxylic acid in $\mathrm{BE}$ reduces it reactivity towards ozone as compared to the methyl ester of COC.

It is important to note that the range of ozone doses used for these experiments is not meant to reflect those typically applied at WWTPs but were chosen to enhance the understanding of the reaction of each drug with ozone. This information can be used when structure elucidation of oxidation transformation products is the ultimate goal, which is the case for this study. Based on the findings presented here, if doses in the range of those typically applied at WWTPs (between 3 and $10 \mathrm{mg} \mathrm{L}^{-1}$ compared to a maximum of $0.30 \mathrm{mg} \mathrm{L}^{-1}$ used to obtain the removal profiles presented here) are applied to wastewater effluent containing these drugs at the same initial concentration, the removals of some compounds would be significantly higher and in some cases complete removal or transformation may be observed, as such a trend was observed during ozonation of other compounds (Oneby et al., 2010; Ried et al., 2009).
Fig. 3 presents the removal data obtained for each of the seven compounds at a ratio of $4: 1$. The first data set is the individual compounds in pure water; the second is a mixture of the compounds in pure water followed by a mixture of the compounds in wastewater, all of which had an initial concentration of $100 \mu \mathrm{g} \mathrm{L}{ }^{-1}$. With the exception of BE, all of the compounds show a significant decrease in their removals when the compounds are combined as a mixture and again when a complex matrix is used. The highest removals were observed for individual compounds in pure water and were between 4 and $42 \%$ followed by a range of 3 to $25 \%$ as a mixture and between 3 and $18 \%$ in wastewater. When individual compounds in pure water are ozonated, the main reaction that occurs is that of the compound being considered with ozone. However, in the case of the mixture, ozone can react with any of the DOAs present in the water and therefore the removals are found to be between 60 and $75 \%$ of the values obtained for individual experiments. Finally, when the matrix is more complex, ozone can react with the DOAs that have been added to the wastewater or any other compounds or organic matter present in the water. As a result, the DOA removal was found to be 31 to $75 \%$ of the values observed in individual solutions in pure water and 50 to $100 \%$ of the values observed in the pure water mixture. These results show that the complexity of the mixture has a direct effect on the removal but to different extents depending on the target compounds and should be taken into consideration when evaluating removals. Simple matrices, such as individual compounds in pure water are however useful for OTP identification and structural elucidation. For such experiments, the OTPs identified are necessarily produced by the transformation of the analyte being considered or the transformation of one of its OTPs and greatly simplify the analysis. The results obtained using pure water can then be validated by confirming the presence of the identified OTPs in the more complex matrix, in our case wastewater. Such experiments were carried out for the DOAs considered in this study and are detailed in the following section.

\subsection{Identification of the main OTPS of the selected DOAs by differential analysis}

The software Sieve 2.0 greatly reduces the time needed to identify potential OTPs however, hundreds of frames are still generated and most of these are due to background noise or contaminants. Therefore, it is necessary to sift through the remaining frames to see which correspond to "true" OTPs. To do so, a series of filters within Sieve can be applied to eliminate frames based on certain criteria. The three criteria

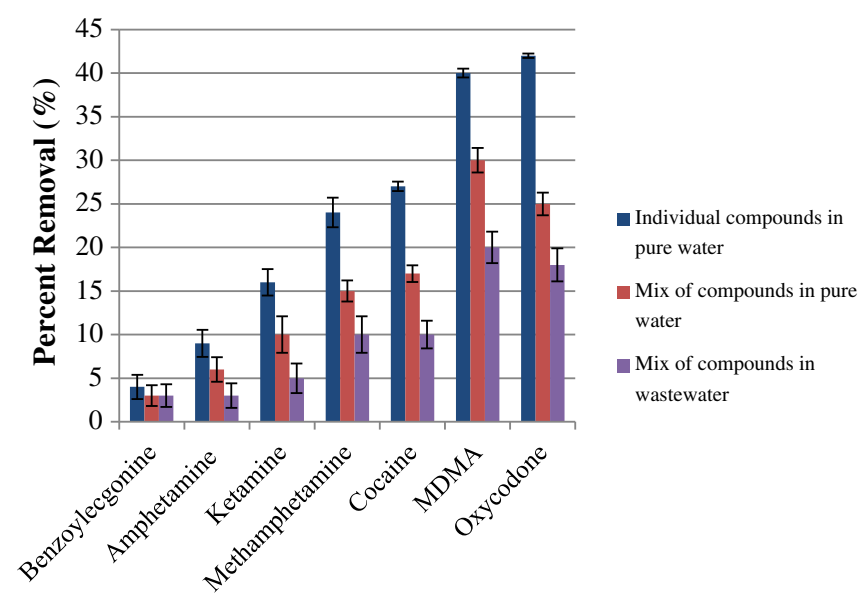

Fig. 3. Average removals of individual DOAs in pure water, as a mixture in pure water and as a mixture in wastewater (in all cases: $C_{o}=100 \mu \mathrm{g} / \mathrm{L}$ and ozone to drug molar ratio $=4: 1$, each data point represents an average of triplicate experiments and error bars correspond to one standard deviation). 
Table 2

Oxidation transformation product summary.

\begin{tabular}{|c|c|c|c|c|c|c|}
\hline Parent compound (chem. formula, $m / z$, RT ( $\mathrm{min}$ )) & OTP name & OTP chem. formula & $\Delta \mathrm{mmu}$ & OTP $m / z$ & OTP retention time (min) & Transient/persistent \\
\hline \multirow[t]{2}{*}{ MDMA $\left(\mathrm{C}_{11} \mathrm{H}_{15} \mathrm{NO}_{2}, 194.1176,1.69\right)$} & OTP-213 & $\mathrm{C}_{10} \mathrm{H}_{16} \mathrm{O}_{4} \mathrm{~N}$ & -1.091 & 214.1073 & 0.52 & Persistent \\
\hline & OTP-229 & $\mathrm{C}_{10} \mathrm{H}_{16} \mathrm{O}_{5} \mathrm{~N}$ & -0.104 & 230.1022 & 1.23 & Transient \\
\hline \multirow{2}{*}{ Cocaine $\left(\mathrm{C}_{17} \mathrm{H}_{21} \mathrm{NO}_{4}, 304.1543,2.08\right)$} & OTP-305 & $\mathrm{C}_{16} \mathrm{H}_{20} \mathrm{O}_{5} \mathrm{~N}$ & -0.199 & 306.1334 & 2.78 & Transient \\
\hline & OTP-319a & $\mathrm{C}_{17} \mathrm{H}_{22} \mathrm{O}_{5} \mathrm{~N}$ & -0.249 & 320.1490 & 3.12 & Transient \\
\hline \multirow[t]{6}{*}{ Oxycodone $\left(\mathrm{C}_{18} \mathrm{H}_{21} \mathrm{NO}_{4}, 316.1543,2.4\right)$} & OTP-381 & $\mathrm{C}_{18} \mathrm{H}_{24} \mathrm{O}_{8} \mathrm{~N}$ & -0.243 & 382.1495 & 1.49 & Persistent \\
\hline & OTP-397 & $\mathrm{C}_{18} \mathrm{H}_{24} \mathrm{O}_{9} \mathrm{~N}$ & -0.258 & 398.1440 & 1.17 & Persistent \\
\hline & OTP-332a & $\mathrm{C}_{15} \mathrm{H}_{25} \mathrm{O}_{8}$ & -1.594 & 333.1528 & 3.18 & Transient \\
\hline & OTP-325 & $\mathrm{C}_{15} \mathrm{H}_{20} \mathrm{O}_{7} \mathrm{~N}$ & -0.028 & 326.1234 & 1.15 & Persistent \\
\hline & ОТР-284 & $\mathrm{C}_{12} \mathrm{H}_{13} \mathrm{O}_{8}$ & -4.694 & 285.0558 & 0.85 & Transient \\
\hline & ОТР367 & $\mathrm{C}_{17} \mathrm{H}_{22} \mathrm{O}_{8} \mathrm{~N}$ & -0.093 & 368.1339 & 1.14 & Persistent \\
\hline
\end{tabular}

${ }^{\text {a }}$ Peak corresponding to the presence of ${ }^{13} \mathrm{C}$.

that each frame was required to meet were: a low intensity in the sample with an ozone to drug ratio of $0: 1$ relative to the $4: 1$ ratio determined as a percent deviation larger than 1000 , a positive slope between the $1: 2$ and $4: 1$ samples and normalized standard deviation (coefficient of variance) lower than 1.8 . The first rule was implemented to avoid the selection of contaminants that are present in high amounts in the non ozonated (0:1) samples. The second rule was implemented since an increase in the intensity of the OTP should be noted as the ozone dose is increased however, since the intensities of the OTPs may also begin to decrease due to their removal at higher ozone doses, the positive slope criteria was chosen to be between samples with no applied ozone and those with a ozone to drug ratio of 4:1. Finally, the third rule was chosen to ensure that random signal spikes, which are likely to have higher variation in the samples, are eliminated. The value of 1.8 for the standard deviation was found to be optimal after a series of preliminary tests were conducted and showed that most of the signal spikes were eliminated without eliminating real peaks.

Very few frames for each compound passed the three criteria described above. This reduced the list of OTPs to just a few per compound as compared to several hundred prior to the filter. The frames that were retained are presented in Table 2 for samples of individual compounds with initial concentration of $5 \mathrm{mg} \mathrm{L}^{-1}$ in pure water. AMP, METH, KET and $\mathrm{BE}$ are absent from Table 2 since none of their frames met all of the criteria and therefore no significant OTPs of these compounds were found in treated solutions for the range of ozone doses and conditions tested. In the case of COC and MDMA, two OTPs were indentified whereas six OTPs met the criteria for OXY. The chemical formulae of each OTP listed in Table 2 were chosen from a short list generated within QualBrowser based on their absolute mass accuracy in milli-mass units $(\Delta \mathrm{mmu})$ and their ring and double bond equivalents (RDBE) value. The OTP retention times are also listed in the table and with the exception of COC's two OTPs and OTP-332 of OXY, all of the OTPs had lower retention times than the parent compound, which can be expected due to the tendency of OTPs to be more hydrophobic than the parent compound (Segura et al., 2013). The "Transient/Persistent" column indicates whether the OTP was detected at an intensity >1E5 at the highest ozone dose tested. Transient OTPs had a peak in intensity at ratios of either $4: 1$ or $2: 1$ and decreased thereafter, indicating that in addition to the parent compound, they too are being removed when higher ozone doses are applied.

The results shown in Table 2 demonstrate that significant OTPs are produced as a result of ozonation of the selected DOAs. In fact, more than half of the identified OTPs are persistent at the highest molar ratio used in this study. This can translate to ozonated wastewater effluent containing these products which is then discharged to receiving waters. In order to validate the results obtained in this study, the ozonation and solid phase extraction of large volumes of unspiked wastewater using the doses applied during spiked-wastewater experiments were carried out. The analysis of these samples by LC-HRMS confirmed the presence of the exact masses of the OTPs of each DOA, confirming their presence in ozonated wastewater. However, in order to further validate the results, it would be necessary to identify these OTPs when ozone doses in the range of 3 to $10 \mathrm{mg} \mathrm{L}^{-1}$ are applied, to be consistent with those used at WWTPs (Oneby et al., 2010; Ried et al., 2009). The results presented here however, reveal that the structural elucidation and an ecotoxicological evaluation of the persistent OTPs are imperative to evaluate the potential effects of the presence of these compounds on aquatic organisms, biota and the ecosystem which have been suggested to be comparable with therapeutic drugs (van Nuijs et al., 2011).

\subsection{Structural elucidation of OTP-213 by HRMS ${ }^{n}$ experiments}

In order to address the potential concerns associated with the presence of OTPs of DOAs in wastewater effluents, experiments were carried out to elucidate the structure of OTP-213 which is the persistent OTP of MDMA identified in this study. After deconvolution of the datadependent ion tree acquisition file, results showed that eight major ions (abundance $>10 \%$ ) were found in the $\mathrm{MS}^{2}$ spectrum, six of which are shown in Fig. 4. All of the ions, with the exception of $\mathrm{m} / \mathrm{z}$ 214.10712 (the precursor ion) and $m / z 168.10160$ (rejected based on intensity), which are omitted from Fig. 4, were selected for $\mathrm{MS}^{3}$ experiments. In the case of $m / z 196.13288$ and $m / z$ 196.09657, since the isolation width was $2 \mathrm{~m} / z$, they were both selected. In the $\mathrm{MS}^{3}$ experiments, at least one second generation product ion was found for each of the $\mathrm{MS}^{2}$ fragments and finally only three third generation product ions were observed (Fig. 4). Based on the chemistry of $\mathrm{O}_{3}$ and the results obtained in Mass Frontier 7.0, three possible structures were proposed for OTP-213 (Table 3) (Decoret et al., 1984). These results were used to assign structures to the observed first, second and third generation product ions (mass accuracy $\leq 10 \mathrm{ppm}$ ). Results showed that for structure OTP-213a, nine product ions out of a possible 37 theoretical (equivalent to 24\%) were observed experimentally. For OTP-213b and OTP-213c, the percentage of experimental ions out of the theoretically possible was 15 and $16 \%$, respectively. This suggests that the most plausible structure among those proposed is the one corresponding to OTP-213a. Unfortunately, this could not be confirmed since, to our

Table 3

Plausible structure of OTP-213 of MDMA.

\begin{tabular}{llll}
\hline OTP name & OTP-213a & OTP-213b & OTP-213c \\
\hline Plausible OTP-213 structures & & & 6 \\
Fragments observed & 9 & 46 & 38 \\
$\quad \begin{array}{l}\text { experimentally } \\
\text { Theoretical fragments }\end{array}$ & 37 & 15 & 16 \\
Experimental/theoretical (\%) $^{\mathrm{c}}$ & 24 & &
\end{tabular}

a Number of fragments observed during $\mathrm{MS}^{\mathrm{n}}$ experiments.

b Number of fragments generated in Mass Frontier.

c Percent of the theoretical fragments observed experimentally. 


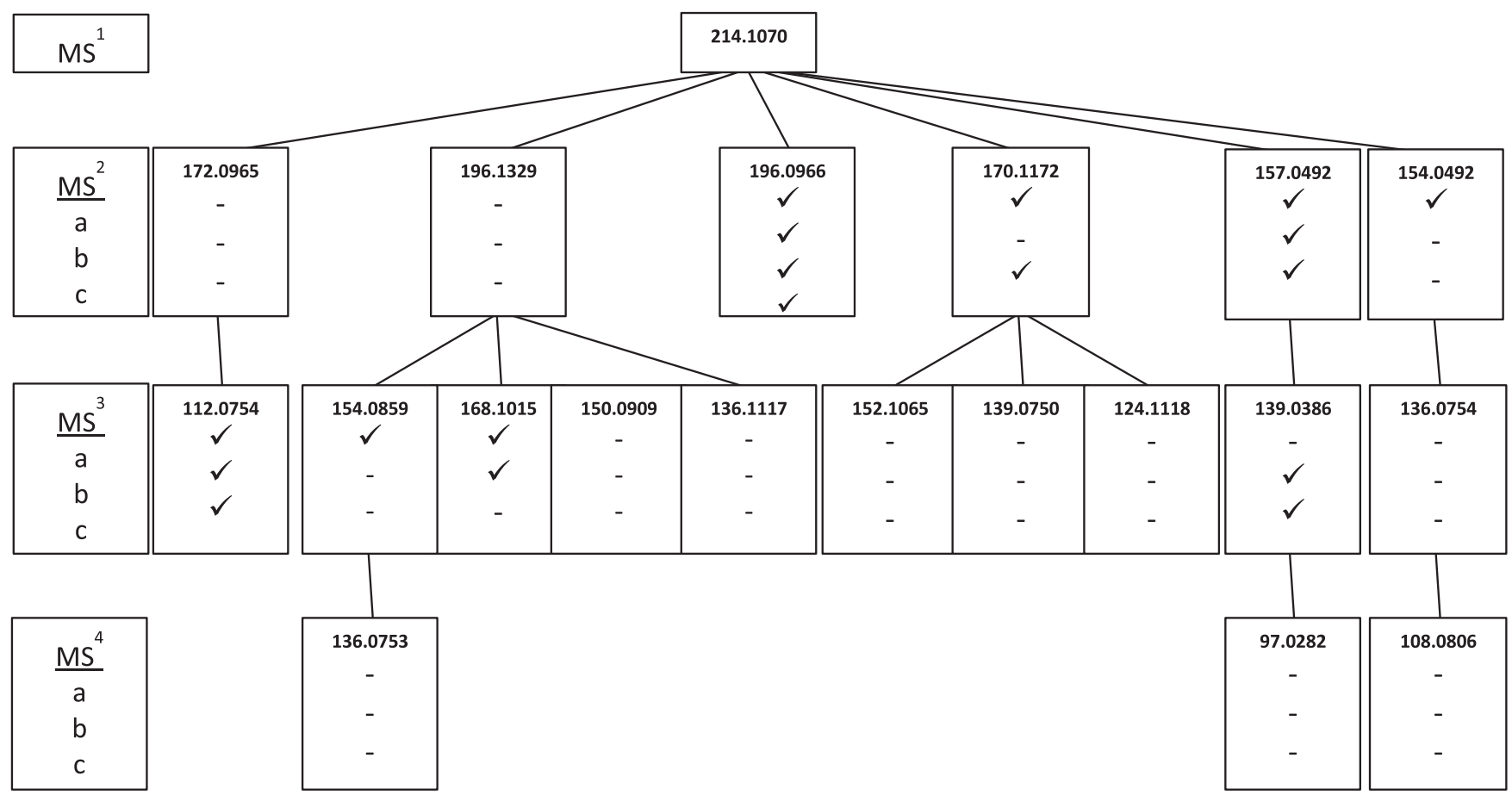

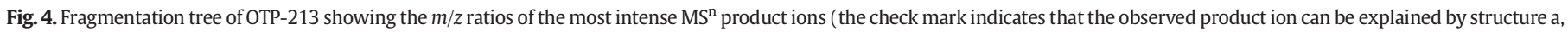
b or $\mathrm{c}$ as denoted in Table 2).

knowledge, commercial isotopically-labeled standards of MDMA do not have isotopes on the benzene ring of the molecule.

\section{Conclusions}

The potential of ozone, used as a disinfectant, to reduce the levels of DOAs in wastewater and the OTPs produced as a result of the treatment was investigated. It was shown that ozone can remove the studied compounds to varying extents, $4-50 \%$, depending on the compound being considered and the applied ozone dose and that further tests should be conducted to investigate the potential to remove these compounds using the ozone doses typically applied at WWTPs for different types of wastewater. The identification of four persistent OTPs of DOAs in ozonated wastewater indicates that although the parent compounds are transformed, it is necessary to consider the nature of these products whereby determining their chemical formulae, structure and potential toxicity. In this study, three plausible structures of the persistent OTP of MDMA with chemical formula $\mathrm{C}_{10} \mathrm{H}_{16} \mathrm{O}_{4} \mathrm{~N}$ were elucidated and the most probable structure was determined to be that of OTP-213a (Table 3). Future considerations include the structural elucidation of the other persistent OTPs that were identified in this study as well as an evaluation of potential chronic effects as a result to long term exposure to low concentrations of the OTPs. This information is needed in order to correctly assess the potential of ozonation to produce treated water that has both reduced levels of DOAs and is indeed less toxic than the untreated water.

Supplementary data to this article can be found online at http://dx. doi.org/10.1016/j.scitotenv.2013.11.023.

\section{Acknowledgments}

We gratefully acknowledge the assistance of the staff at the wastewater treatment plant for collecting the samples. This work was supported by the Natural Sciences and Engineering Council (NSERC) of Canada through a Discovery grant and a Strategic Project grant to Dr. Yargeau. We thank NSERC for a post graduate doctoral scholarship awarded to Angela Rodayan and for a postdoctoral fellowship awarded to Pedro A. Segura. We also thank the Fonds québécois de la recherche sur la nature et les technologies for a doctoral scholarship awarded to Angela Rodayan.

\section{References}

Akmehmet Balcıoğlu I, Arslan Alaton I, Ötker M, Bahar R, Bakar N, Ikiz M. Application of advanced oxidation processes to different industrial wastewaters. J Environ Sci Health A 2003;38:1587-96.

Bader $\mathrm{H}$, Hoigne J. Determination of ozone in water by the indigo method. Water Res 1981:15:449-56.

Baker DR, Kasprzyk-Hordern B. Multi-residue analysis of drugs of abuse in wastewater and surface water by solid-phase extraction and liquid chromatography-positive electrospray ionisation tandem mass spectrometry. J Chromatogr A 2011;1218:1620-31.

Bartelt-Hunt SL, Snow DD, Damon T, Shockley J, Hoagland K. The occurrence of illicit and therapeutic pharmaceuticals in wastewater effluent and surface waters in Nebraska. Environ Pollut 2009;157:786-91.

Bijlsma L, Sancho JV, Pitarch E, Ibáñez M, Hernández F. Simultaneous ultra-high-pressure liquid chromatography-tandem mass spectrometry determination of amphetamine and amphetamine-like stimulants, cocaine and its metabolites, and a cannabis metabolite in surface water and urban wastewater. J Chromatogr A 2009;1216:3078-89.

Bijlsma L, Emke E, Hernández F, de Voogt P. Investigation of drugs of abuse and relevant metabolites in Dutch sewage water by liquid chromatography coupled to high resolution mass spectrometry. Chemosphere 2012;89:1399-406.

Bijlsma L, Emke E, Hernández F, de Voogt P. Performance of the linear ion trap Orbitrap mass analyzer for qualitative and quantitative analysis of drugs of abuse and relevant metabolites in sewage water. Anal Chim Acta 2013;768:102-10.

Boleda MR, Galceran MT, Ventura F. Trace determination of cannabinoids and opiates in wastewater and surface waters by ultra-performance liquid chromatography-tandem mass spectrometry. J Chromatogr A 2007;1175:38-48.

Boleda MR, Galceran MT, Ventura F. Monitoring of opiates, cannabinoids and their metabolites in wastewater, surface water and finished water in Catalonia, Spain. Water Res 2009;43:1126-36.

Boleda MR, Huerta-Fontela M, Ventura F, Galceran MT. Evaluation of the presence of drugs of abuse in tap waters. Chemosphere 2011;84:1601-7.

Bolong N, Ismail AF, Salim MR, Matsuura T. A review of the effects of emerging contaminants in wastewater and options for their removal. Desalination 2009;239:229-46.

Bones J, Thomas KV, Paull B. Using environmental analytical data to estimate levels of community consumption of illicit drugs and abused pharmaceuticals. J Environ Monitor 2007:9.

Boxall ABA, Rudd MA, Brooks BW, Caldwell DJ, Choi K, Hickmann S, et al. Pharmaceuticals and personal care products in the environment: what are the big questions? Environ Health Perspect 2012;120:1221.

Camacho-Muñoz MD, Santos JL, Aparicio I, Alonso E. Presence of pharmaceutically active compounds in Doñana Park (Spain) main watersheds. J Hazard Mater 2010;177: 1159-62. 
Castiglioni S, Bagnati R, Fanelli R, Pomati F, Calamari D, Zuccato E. Removal of pharmaceuticals in sewage treatment plants in Italy. Environ Sci Technol 2006a;40:357-63.

Castiglioni S, Zuccato E, Crisci E, Chiabrando C, Fanelli R, Bagnati R. Identification and measurement of illicit drugs and their metabolites in urban wastewater by liquid chromatography-tandem mass spectrometry. Anal Chem 2006b;78:8421-9.

Celiz MD, Tso J, Aga DS. Pharmaceutical metabolites in the environment: analytical challenges and ecological risks. Environ Toxicol Chem 2009;28:2473-84.

Chiaia AC, Banta-Green C, Field J. Eliminating solid phase extraction with large-volume injection LC/MS/MS: analysis of illicit and legal drugs and human urine indicators in US wastewaters. Environ Sci Technol 2008;42:8841-8.

Comninellis C, Kapalka A, Malato Sixto, Parsons SA, Poulios I, Mantzavinos D. Advanced oxidation processes for water treatment: advances and trends for R\&D. J Chem Technol Biotechnol 2008;83:769-76.

Dantas RF, Canterino M, Marotta R, Sans C, Esplugas S, Andreozzi R. Bezafibrate removal by means of ozonation: primary intermediates, kinetics, and toxicity assessment. Water Res 2007;41:2525-32.

de Jongh CM, Kooij PJF, de Voogt P, ter Laak TL. Screening and human health risk assessment of pharmaceuticals and their transformation products in Dutch surface waters and drinking water. Sci Total Environ 2012;427-428:70-7.

Decoret C, Royer J, Legube B, Dore M. Experimental and theoretical studies of the mechanism of the initial attack of ozone on some aromatics in aqueous medium. Environ Technol Lett 1984:5:207-18.

Gheorghe A, van Nuijs A, Pecceu B, Bervoets L, Jorens PG, Blust R, et al. Analysis of cocaine and its principal metabolites in waste and surface water using solid-phase extraction and liquid chromatography-ion trap tandem mass spectrometry. Anal Bioanal Chem 2008;391:1309-19.

Gogate PR, Pandit AB. A review of imperative technologies for wastewater treatment II: hybrid methods. Adv Environ Res 2004;8:553-97.

Gomez-Ramos M, Mezcua M, Aguera A, Fernandez-Alba AR, Gonzalo S, Rodriguez A, et al Chemical and toxicological evolution of the antibiotic sulfamethoxazole under ozone treatment in water solution. J Hazard Mater 2011;192:18-25.

Gonzalez-Marino I, Benito Quintana J, Rodriguez I, Cela R. Determination of drugs of abuse in water by solid-phase extraction, derivitisation and gas chromatography-ion trap-tandem mass spectrometry. J Chromatogr A 2010;1217:1748-60.

González-Mariño I, Quintana JB, Rodríguez I, González-Díez M, Cela R. Screening and selective quantification of illicit drugs in wastewater by mixed-mode solid-phase extraction and quadrupole-time-of-flight liquid chromatography-mass spectrometry. Anal Chem 2011;84:1708-17.

Halling-Sørensen B, Nors Nielsen S, Lanzky PF, Ingerslev F, Holten Lützhøft HC, Jørgensen SE. Occurrence, fate and effects of pharmaceutical substances in the environment - a review. Chemosphere 1998;36:357-93.

Hollender J, Zimmermann SG, Koepke S, Krauss M, Mcardell CS, Ort C, et al. Elimination of organic micropollutants in a municipal wastewater treatment plant upgraded with a full scale post-ozonation followed by sand filtration. Environ Sci Technol 2009;43: 7862-9.

Huber MM, Canonica S, Park G-Y, Von Gunten U. Oxidation of pharmaceuticals during ozonation and advanced oxidation processes. Environ Sci Technol 2003;37:1016-24.

Huber MM, Gobel A, Joss A, Herrmann N, Loffler D, Mcardell C, et al. Oxidation of pharmaceuticals during ozonation of municipal wastewater effluents: a pilot study. Environ Sci Technol 2005;39:4290-9.

Huerta-Fontela M, Galceran MT, Ventura F. Ultraperformance liquid-chromatographytandem mass spectrometry analysis of stimulatory drugs of abuse in wastewater and surface waters. Anal Chem 2007;79:3821-9.

Huerta-Fontela M, Galceran MT, Ventura F. Stimulatory drugs of abuse in surface waters and their removal in a conventional drinking water treatment plant. Environ Sci Technol 2008;42:6809-16.

Huerta-Fontela M, Pineda O, Ventura F, Galceran MT. New chlorinated amphetaminetype-stimulants disinfection-by-products formed during drinking water treatment. Water Res 2012;46:3304-14.

Hummel D, Loeffler D, Fink G, Ternes TA. Simultaneous determination of psychoactive drugs and their metabolites in aqueous matrices by liquid chromatography mass spectrometry. Environ Sci Technol 2006:40.

Irvine RJ, Kostakis C, Felgate PD, Jaehne EJ, Chen C, White JM. Population drug use in Australia: a wastewater analysis. Forensic Sci Int 2011;210:69-73.

Jones-Lepp TL, Alvarez DA, Petty JD, Huckins JN. Polar organic chemical integrative sampling and liquid chromatography-electrospray/ion-trap mass spectrometry for assessing selected prescription and illicit drugs in treated sewage effluents. Arch Environ Contam Toxicol 2004:47:427-39.

Joss A, Siegrist H, Ternes TA. Are we about to upgrade wastewater treatment for removing organic micropollutants. Water Sci Technol 2008;57:251-5.

Kantiani L, Farre M, Postigo C, de Alda MJ Lopez, Barcelo D. Aquatic ecotoxicity assessment of illicit drugs by Daphnia magna, Selenastrum capricornutum and Vibrio fisheri. SETAC 2010. Spain: Seville; 2010.

Kasprzyk-Hordern B, Dinsdale RM, Guwy AJ. Illicit drugs and pharmaceuticals in the environment - forensic applications of environmental data. Part 1: estimation of the usage of drugs in local communities. Environ Pollut 2009;157:1773-7.

Kasprzyk-Hordern B, Vishnu VRK, Baker DR. Enantioselective occurrence of chiral drugs of abuse in the environment. SETAC 2010. Spain: Seville; 2010.

Klavarioti M, Mantzavinos D, Kassinos D. Removal of residual pharmaceuticals from aqueous systems by advanced oxidation processes. Environ Int 2009;35:402-17.

Kolpin DW, Furlong E, Meyer MT, Thurman E, Zaugg S, Barber L, et al. Pharmaceuticals, hormones, and other organic wastewater contaminants in US streams 1999-2000: a national reconnaissance. Environ Sci Technol 2002;36:1202-11.
Larcher S, Yargeau V. The effect of ozone on the biodegradation of $17 \alpha$-ethinylestradiol and sulfamethoxazole by mixed bacterial cultures. Appl Microbiol Biotechnol 2013;97: 2201-10.

Martínez Bueno MJ, Uclés S, Hernando MD, Fernández-Alba AR. Development of a solvent-free method for the simultaneous identification/quantification of drugs of abuse and their metabolites in environmental water by LC-MS/MS. Talanta 2011;85:157-66.

McDowell D, Huber MM, Wagner M, Von Guntern U, Ternes TA. Ozonation of carbamazepine in drinking water: identification and kinetic study of major oxidation products. Environ Sci Technol 2005;39:8014-22.

Metcalfe CD, Koenig BG. Occurrence of neutral and acidic drugs in the effluents of Canadian sewage treatment plants. Environ Toxicol Chem 2003;22:2872-80.

Metcalfe C, Tindale K, Li H, Rodayan A, Yargeau V. Illicit drugs in Canadian municipal wastewater and estimates of community drug use. Environ Pollut 2010;158: 3179-85.

Nakada N, Shinohara H, Murata A, Kiri K, Managaki S, Sato N, et al. Removal of selected pharmaceuticals and personal care products (PPCPs) and endocrine-disrupting chemicals (EDCs) during sand filtration and ozonation at a municipal sewage treatment plant. Water Res 2007;41:4373-82.

Nasuhoglu D, Rodayan A, Berk D, Yargeau V. Removal of the antibiotic levofloxacin (LEVO) in water by ozonation and TiO2 photocatalysis. Chem Eng J 2012;189-190 41-8.

Nuijs AN, Tarcomnicu I, Bervoets L, Blust R, Jorens P, Neels H, et al. Analysis of drugs of abuse in wastewater by hydrophilic interaction liquid chromatography-tandem mass spectrometry. Anal Bioanal Chem 2009;395:819-28.

Oneby MA, Bromley CO, Borchardt JH, Harrison DS. Ozone treatment of secondary effluent at U.S. municipal wastewater treatment plants. Ozone Sci Eng 2010;32: 43-55.

Pal R, Megharaj M, Kirkbride KP, Naidu R. Illicit drugs and the environment - a review. Sci Total Environ 2013;463-464:1079-92.

Pedrouzo M, Borrull F, Pocurull E, Marce R. Drugs of abuse and their metabolites in waste and surface waters by liquid chromatography tandem mass spectrometry. J Sep Sci 2011a;34:1091-101.

Pedrouzo M, Borrull F, Pocurull E, Marcé RM. Drugs of abuse and their metabolites in waste and surface waters by liquid chromatography-tandem mass spectrometry. J Sep Sci 2011b;34:1091-101.

Postigo C, de Alda MJ Lopez, Barcelo D. Drugs of abuse and their metabolites in the Ebro River Basin: occurrence in sewage and surface water, sewage treatment plants removal efficiency, and collective drug usage estimation. Environ Pollut 2010;36: 75-84.

Postigo C, Lopez de Alda MJ, Barcelo D. Occurrence of illicit drugs in wastewater in Spain. In: Castiglioni S, Zuccato E, Fanelli R, editors. Illicit drugs in the environment: occurrence, analysis, and fate using mass spectrometry. Hobokenm, New Jersey: John Wiley \& Sons Inc.; 2011. p. 117-36.

Ried A, Mielcke J, Wieland A. The potential use of ozone in municipal wastewater. Ozone Sci Eng 2009;31:415-21.

Rodayan A, Roy R, Yargeau V. Oxidation products of sulfamethoxazole in ozonated secondary effluent. J Hazard Mater 2010;177:237-43.

Rosal R, Rodríguez A, Perdigón-Melón JA, Petre A, García-Calvo E, Gómez MJ, et al. Occurrence of emerging pollutants in urban wastewater and their removal through biological treatment followed by ozonation. Water Res 2010;44:578-88.

Segura P, Kaplan P, Yargeau V. Identification and structural elucidation of ozonation transformation products of estrone. Chem Cent J 2013;7:74.

Ternes TA. Occurrence of drugs in German sewage treatment plants and rivers. Water Res 1998:32.

Ternes TA, Stuber J, Hermann N, McDowell D, Ried A, Kampmann M, et al. Ozonation: a tool for removal of pharmaceuticals, contrast media and musk fragrances from wastewater? Water Res 2003;37:1976-82.

Terzic S, Senta I, Ahel M. Illicit drugs in wastewater of the city of Zagreb (Croatia) estimation of drug abuse in a transition country. Environ Pollut 2010;158:2686-93.

UNODC. World Drug Report 2008. Vienna, Austria: United Nations Office on Drugs and Crime; 2008.

Valcárcel Y, Martínez F, González-Alonso S, Segura Y, Catalá M, Molina R, et al. Drugs of abuse in surface and tap waters of the Tagus River basin: heterogeneous photo-Fenton process is effective in their degradation. Environ Int 2012;41:35-43.

van Nuijs ALN, Mougel J-F, Tarcomnicu I, Bervoets L, Blust R, Jorens PG, et al. A one year investigation of the occurrence of illicit drugs in wastewater from Brussels, Belgium. J Environ Monit 2011;13:1008-16.

von Gunten U. Ozonation of drinking water: part I. Oxidation kinetics and product formation. Water Res 2003;37:1443-67.

Wert EC, Rosario-Ortiz FL, Snyder SA. Effect of ozone exposure on the oxidation of trace organic contaminants in wastewater. Water Res 2009;43:1005-14.

Yargeau V, Taylor B, Li H, Rodayan A, Metcalfe C. Analysis of drugs of abuse in wastewater from two Canadian cities. Sci Total Environ 2013: Unpublished results.

Zuccato E, Castiglioni S. Illicit drugs in the environment. Philos Trans R Soc A 2009;367: 3965-78.

Zuccato E, Chiabrando C, Castiglioni S, Calamari D, Bagnati R, Schiarea S, et al. Cocaine in surface waters: a new evidence-based tool to monitor community drug abuse. Environ Health 2005:4

Zuccato E, Castiglioni S, Bagnati R, Chiabrando C, brassi P, Fanelli R. Illicit drugs, a nove group of environmental contaminants. Water Res 2008;42:961-8.

Zwiener C, Frimmel FH. Oxidative treatment of pharmaceuticals in water. Water Res 2000;34:1881-5. 